\title{
The Prevalence of Oral Lesions among Palestinian Dental Patients Attending Oral Medicine Dental Clinics at Al-Quds University
}

\author{
F. S. Habash, A. Ismail, R. O. Abu Hantash, M. Abu Younis \\ Faculty of Dentistry, Al-Quds University, Jerusalem, Palestine \\ Email:abuhantash@yahoo.com,rhantash@staff.alquds.edu
}

How to cite this paper: Habash, F.S., Ismail, A., Abu Hantash, R.O. and Abu Younis, M. (2020) The Prevalence of Oral Lesions among Palestinian Dental Patients Attending Oral Medicine Dental Clinics at Al-Quds University. Open Journal of Stomatology, 10, 300-309.

https://doi.org/10.4236/ojst.2020.1010028

Received: May 15, 2020

Accepted: October 23, 2020

Published: October 26, 2020

Copyright $\odot 2020$ by author(s) and Scientific Research Publishing Inc. This work is licensed under the Creative Commons Attribution International License (CC BY 4.0).

http://creativecommons.org/licenses/by/4.0/

(c) (i) Open Access

\begin{abstract}
Objectives: In Palestine, there are no data about the prevalence of oral lesions or their associated risk factors. Thus, this study came to assess the prevalence and the risk factors of oral lesions among adult dental patients visiting AlQuds University (AQU) Dental Clinics. Materials and Methods: Three hundred Twenty patients were diagnosed clinically for the presence of oral lesions at oral medicine clinics at Al-Quds University in the period between 2015 to 2016. Their age ranged from 21 to 60 years old (mean age: $40.2 \pm 17.6$ ). Senior students were trained to conduct the oral exam under the direct supervision of Oral Medicine specialist. Trained students also collected data on patients' demographics, dental history, medical history and other health related habits. Descriptive and bivariate analyses were generated to describe lesions prevalence and associations with other suggested factors. Results: A total of 68 lesions were found in this study (29.4\% of study's sample). Recurrent aphthous ulcer, traumatic ulcer and geographic tongue were the most common oral lesions. Ten oral potentially malignant lesions were diagnosed (8 cases were Leukoplakia, 2 cases were erythroplakia). Non filtered smoking cigarettes were associated with reported lesions. Oral lesions were noticed to increase with age. Oral lesions were more common on the Tongue, labial and buccal mucosain this study. Conclusions: This study revealed high prevalence of apthous and traumatic ulcer while potentially malignant lesions like leucoplakia and erythroplakia were also seen in patients who were smokers. Dentists should have a high level of awareness during oral examination and intervention should be performed to raise awareness among the population about the harmful effects of smoking on oral health.
\end{abstract}

\section{Keywords}

Oral Lesions, Potentially Malignant, Smoking Habits 


\section{Introduction}

Oral soft tissue lesions present a significant health problem with a considerable morbidity. Despite its importance, there are no reports on its prevalence among the Palestinian population and its association with oral habits, when compared to dental caries and periodontal diseases.

Among Saudi dental patients, the most commonly affected age group was 31 to 40 years. The least affected age group were individuals older than 61 years. The most common lesion was Fordyce granules followed by leukoedema and traumatic lesions (ulcer, erosion) [1].

While in Yemeni dental patients, oral mucosal lesions and their association with tobacco use and qat chewing were evident. There were some differences in the distribution of oral mucosal conditions among sexes. Fissured tongue, hairy tongue, qat-induced white lesions and leukoedema were significantly associated with men. Atrophic tongue showed a weak association with gender. Cheek biting and geographic tongue were found to be more common among women. There was a significant increase in the incidence of, fissured tongue, leukoplakia, and exophytic lesions with age [2].

Among elderly dental patients in Sana'a and Yemen, the prevalence rate of oral mucosal lesions indicated a significant decrease with advancing age. The most frequently observed lesions were fissured tongue, benign tumors, hairy tongue, and qat-induced white lesions. Hairy tongue, qat-induced white lesions, and shammah keratosis were associated with men, whereas geographic tongue was associated with women. The presence of one or more lesions was significantly associated with low education level. Certain lesions showed a significant association with smoking and qat chewing. No association was found between the occurrence of oral lesions and denture wearing [3].

Patients attending College of Dentistry, University of Dammam: A clinicopathological study showed that Denture-induced fibrous hyperplasia was the most common type of lesion detected [4].

Among Libyan population, Pyogenic granuloma, lichen planus, radicular cyst and fibroepithelial polyp were found to be the most predominant lesions [5].

Oral Mucosal Lesions among Indians from Northeast Brazil, the most prevalent lesions were fistulae and traumatic ulcers. Oral lesions were associated with higher age [6].

Oral mucosal diseases, salivary dysfunction, and limited mouth-opening were described in Oral Disease Profiles in Chronic Graft versus Host Disease study [7].

The results of 1013 Jordanians dental outpatients showed that 240 subjects $(23.7 \%)$ had one or more tongue lesions. the most common lesion was fissured tongue $(11.4 \%)$ followed by geographic tongue $(6.8 \%)$, then hairy tongue $(3.4 \%)$ [8].

In a study showing the relation between some habits (smoking smokeless tobacco and alcohol) and oral lesions, it was found that such habits are more 
common in males. Smoking was the most common habit (39.2\%), followed by smokeless tobacco (28.1\%). Leukoplakia was found to be the most common lesion in patients with such habits [11].

Few studies have been conducted on oral mucosal lesions. None of them was conducted in Palestine. The purpose of this study was to evaluate the type and extent of oral lesions among Palestinian dental patients of Al-Quds University oral medicine and diagnosis clinic. This observational study was done to evaluate the prevalence of oral mucosal lesions, and their risk indicators in dental patients of Al-Quds University oral medicine and diagnosis clinic for a period of Twelve months between September 2015 to August 2016.

The aim of this study was to assess the prevalence of oral lesions among dental patients of Al-Quds University oral medicine and diagnosis clinic and to determine the association between these conditions and age, gender, income, educational level, diabetic status, and smoking habits.

\section{Methods}

This study was carried out in the School of Dental Medicine of Al-Quds University located in Jerusalem, Abu Dis Campus. Patients attending the Oral Medicine and Diagnosis clinics were examined by fifth year (senior) dental students. An informed consent was asked, and the examination was supervised and checked by two oral medicine specialists. The two specialists were calibrated by discussing diagnosis criteria extensively. An oral mucosal assessment questionnaire which was validated by experts and was created for the purpose of the study based on previous surveys [4] [5] [6] [7]. The questionnaire is comprised of four major sections: patient's information, patient's medical history, dental history, and oral mucosal diseases. Stress level scale was introduced to the patients and they were asked to rate/rank their stress level from $1-10$.

In the information section of the assessment consisted of questions regarding place of residence, occupation, smoking habits and educational background. The medical history section consisted of questions about previous hospitalizations, current medications and allergies. Moreover, a list of diseases was presented to the patients allowing them to choose if they currently have or previously had any of the conditions presented. The dental history section encompasses several inquiries including the patient's oral hygiene habits, dentist visits, and other modifying factors that may be correlated with oral lesions such as denture wearing. The fourth section of the assessment form is based on the clinical examination of the patient. Oral mucosal disorders are listed in a table. The student had to report the presence or absence of the each of the disorders presented. Locations in the oral cavity were coded with numbers and students were required to enter appropriate codes

The two supervising oral medicine specialists trained the students on how to use the form. They ensured calibration of fifth year (senior) dental students by supervising the process of patient examination and data input. Histopathological 
examination was indicated for suspected potentially malignant lesions.

This study was conducted over a period of six months and Three hundred and fourteen patients were examined. The data collected was entered into the SPSS (Version 20). The variables were cross tabulated and Chi-squared tests were carried out. Statistical significance was set at a $\mathrm{P}$ value $<0.05$.

\section{Results}

The mean age of participants in this study was 40.2 years \pm 17.6 . The majority (40.5\%) were adults between 41 - 60 years old. Almost an equal number of males and females were examined (males $=51.3 \%$ ). Geographically, $68.9 \%$ of the patients came from the middle of the West Bank (mention names of the cities included in each part in the methods section), whilst $26.8 \%$ and $2.4 \%$ came from its southern and northern parts, respectively (Figure 1).

Access to care were quantified by "the most recent visit to the Dentist" variable. In the past 6 months $41.5 \%$ of the patients visited the dentist, while $26.1 \%$ visited their dentist in the past 6 months - 1 year and $29.3 \%$ haven't visited their dentist for more than 1 year. 3.5\% never visited a dentist. Reasons behind visiting the dentist are shown in Figure 2.

Almost $24 \%$ of the sample never brushed their teeth. More about oral hygiene habits are found in Figure 3 and Figure 4. 72\% of study particpants had high school diploma or less (Figure 5).

In this study, 32\% of particpants had smoking history (Figure 6). (76.8\% smoked cigarettes, $20.2 \%$ smoked narghile, $2 \%$ pipe and other forms $1 \%$ ). Those smoking cigarettes could be classified into categories regarding their smoking habits: $11.7 \%$ smoked 1 - 5 cigarettes/day, 11.7\% smoked 5 - 10 cigarettes/day, $40.3 \%$ smoked 10 - 20 cigarettes/day, $29.9 \%$ smoked cigarettes/day, and $6.5 \%$ smoked more than 40 cigarettes/day.

Medical status of the patients were as follows, $27 \%$ were undergoing some form of medical Treatment, $24.2 \%$ are taking medications, 34 patients had diabetes $(10.8 \%)$, and $0.3 \%$ reported Hepatitis $B$.

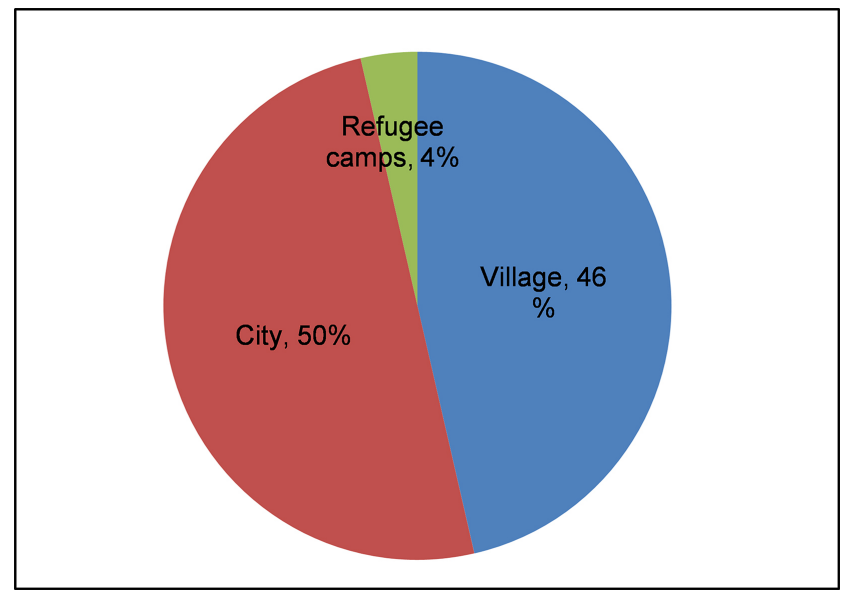

Figure 1. Place of residence. 


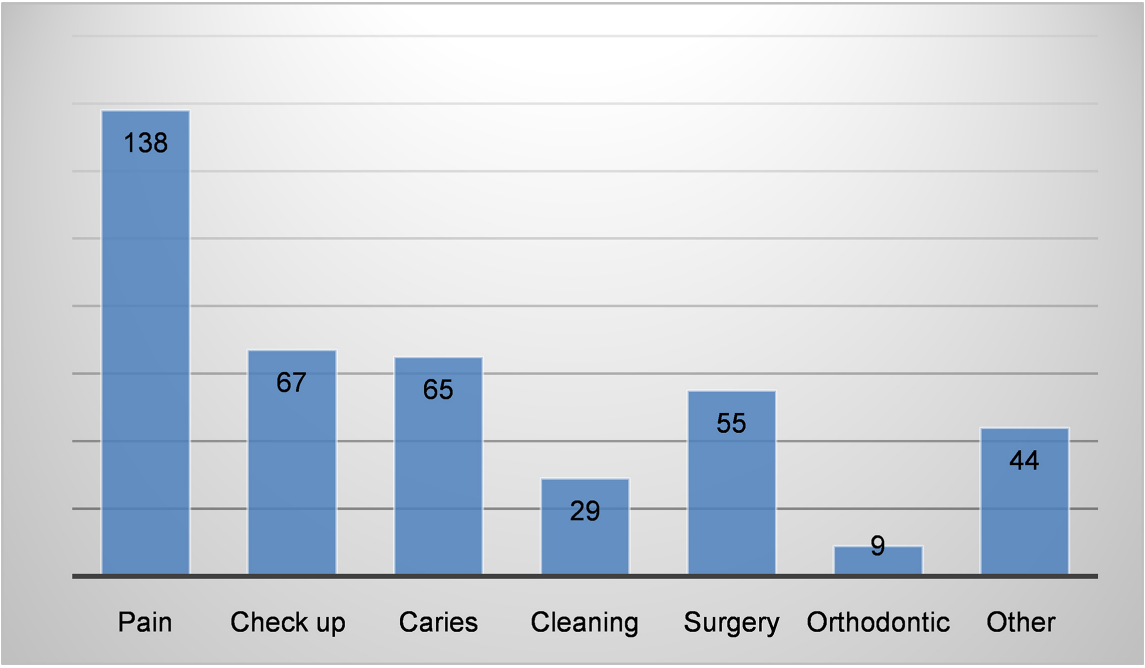

Figure 2. Reasons behind visiting the dentist.

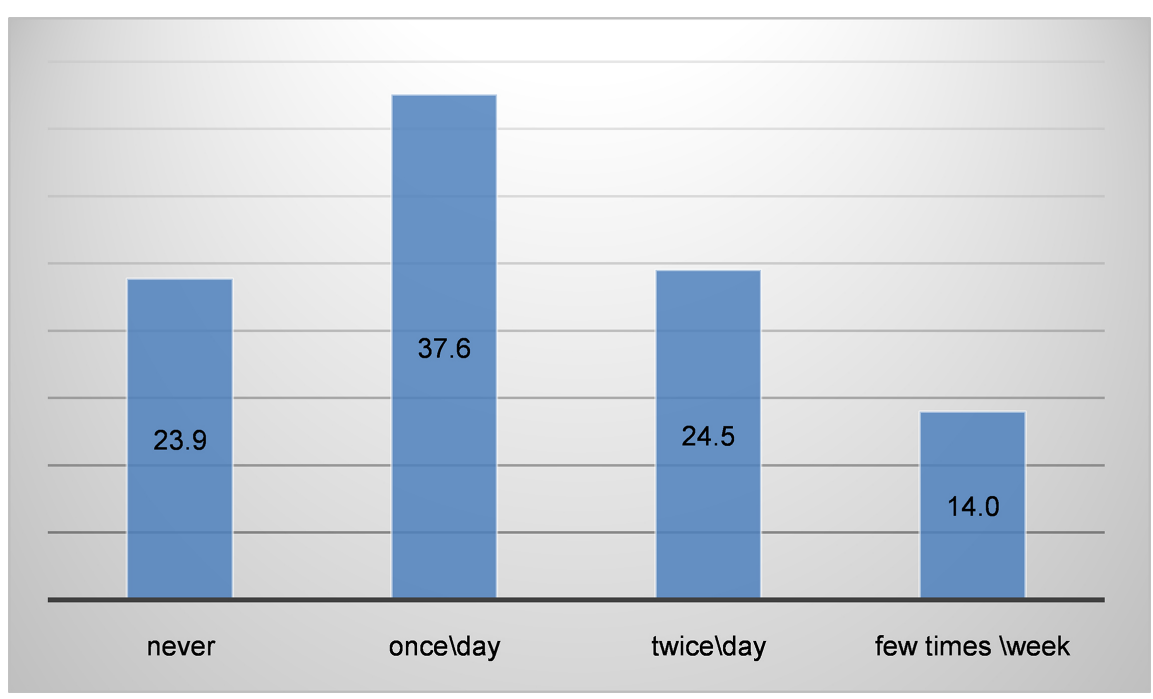

Figure 3. Brushing frequency.

\begin{tabular}{|c|c|}
\hline \multicolumn{2}{|c|}{ Other Cleaning Means } \\
\hline $11.5 \%$ & Dental Floss \\
\hline $8 \%$ & Mouth Rinse \\
\hline $3.2 \%$ & Siwak \\
\hline $2.2 \%$ & Sugarless gum \\
\hline $6.7 \%$ & Toothpicks \\
\hline $1 \%$ & Interproximal brushes \\
\hline
\end{tabular}

Figure 4. Other cleaning methods used. 


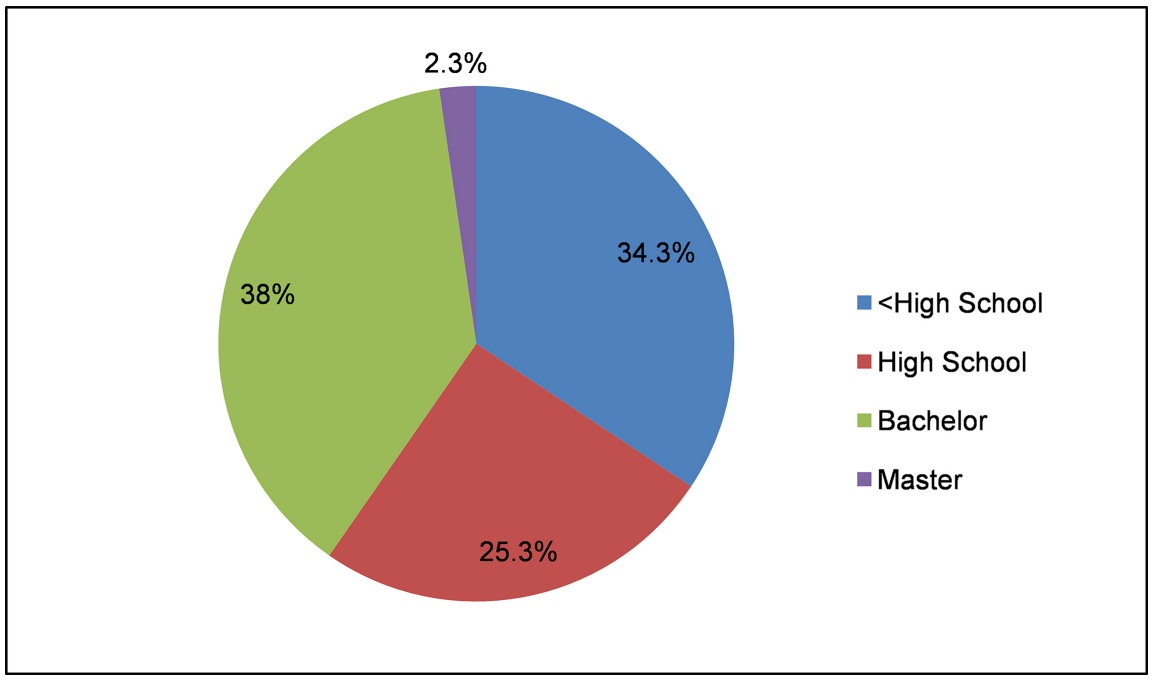

Figure 5. Education level of participants.

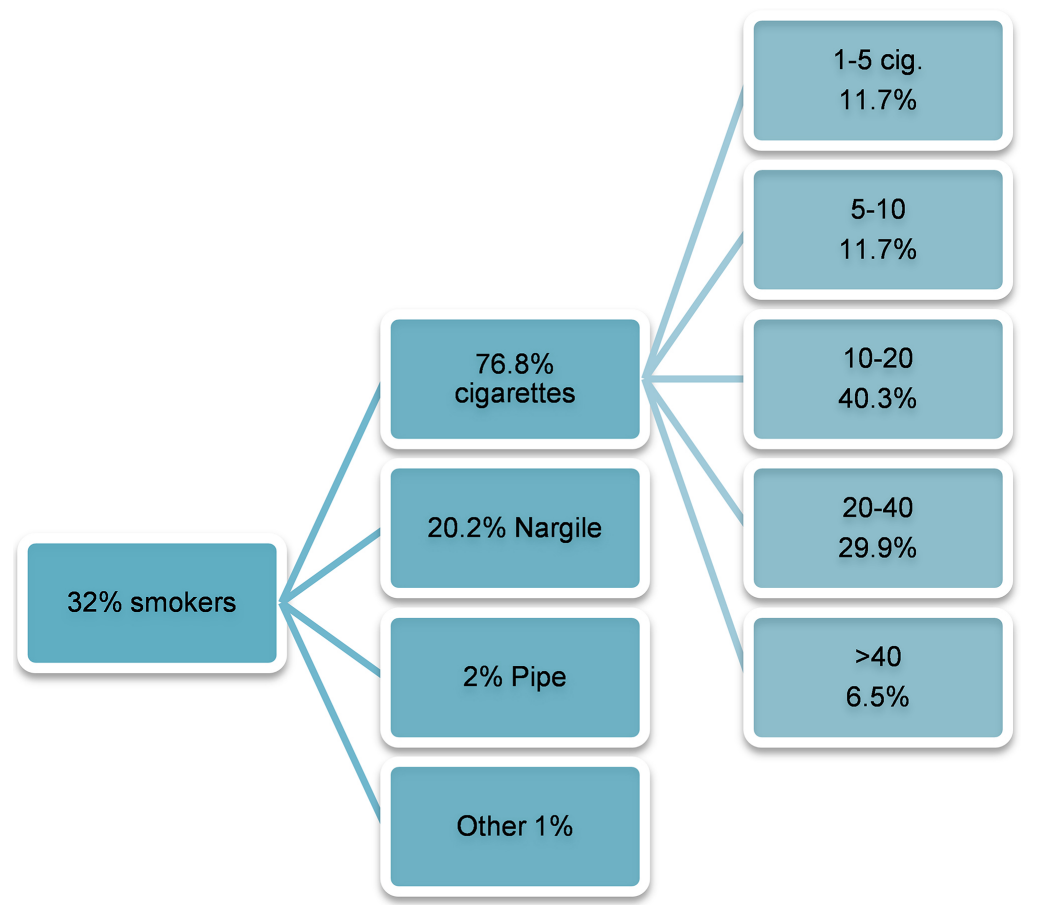

Figure 6. Smoking habits.

Among women in our sample, $1 \%$ were nursing mothers, $0.3 \%$ were pregnant and $0.6 \%$ were on birth control pills. Dental history of the participants revealed that, $17.2 \%$ (54 patients) had dentures.

A total of 68 lesions were identified. The prevalence of oral mucosal lesions among patients was $22 \%$. The most common lesion was recurrent aphthous stomatitis- 9 cases followed by fibroepithelial polyp ( 8 cases), frictional keratosis, smooth fissured leukoplakia and traumatic ulcers -7 cases each. Other lesions seen were Chronic atrophic candidiasis And two cases with oralcarcinoma were detected. The most affected site was the buccal mucosa (Table 1). 
Table 1. Shows prevalence of oral lesions.

\begin{tabular}{|c|c|c|}
\hline Lesion & Number of Cases & Percentage \% \\
\hline Lichen Planus & 1 & 1.5 \\
\hline Hyperplastic Candidosis & 1 & 1.5 \\
\hline Nicotinic Stomatitis & 1 & 1.5 \\
\hline Behcet Disease & 1 & 1.5 \\
\hline Bone Exostosis & 1 & 1.5 \\
\hline Fibrous Epulis & 1 & 1.5 \\
\hline Squamous Cell Papilloma & 1 & 1.5 \\
\hline Lymphangioma & 1 & 1.5 \\
\hline Carcinoma & 2 & 2.9 \\
\hline Erythroplakia & 2 & 2.9 \\
\hline Herpes Labialis & 2 & 2.9 \\
\hline Epulis Fissuratum & 2 & 2.9 \\
\hline Actinic Cheilitis & 2 & 2.9 \\
\hline Angular Cheilitis & 3 & 4.4 \\
\hline Fibroma & 3 & 4.4 \\
\hline Chronic Atrophic Candidiasis & 6 & 8.8 \\
\hline Smooth Fissured Leukoplakia & 7 & 10.3 \\
\hline Traumatic Ulcer & 7 & 10.3 \\
\hline Frictional Keratosis & 7 & 10.3 \\
\hline Fibroepithelial Polyp & 8 & 11.8 \\
\hline Recurrent Aphthus Ulcer & 9 & 13.2 \\
\hline Totlal & 68 & 100 \\
\hline
\end{tabular}

\section{Discussion}

The oral mucosa is an integral anatomic structure of the oral cavity. It precludes harmful pathogens from entering the body. Many systemic diseases and/or conditions have an oral mucosal manifestation [9] [10]. Therefore, regular patient visits to the dental office and regular examination of the oral mucosa is an essential measure of unveiling underlying systemic and even local diseases/conditions (e.g. oral cancer).

A similar study which was conducted in Jordan, 2000 dental outpatients were examined to see any tongue lesions. The most common tongue lesion found was fissured tongue (11.5\%), followed by coated tongue (8.2\%), then geographic tongue $(4.8 \%)$, and hairy tongue (2.4\%). Median rhomboid glossitis was diagnosed 
in $0.5 \%$ of patients. Most of patients were not aware of their tongue lesions [10].

In a study showing the prevalence and awareness regarding oral potentially malignant lesions in Jordanian population, a total of 1041 patients were examined and the prevalence of oral potentially malignant lesions was found to be $2.8 \%$. The most common found lesions were lichenoid lesions (1.8\%), followed by leukoplakias $(0.48 \%)$, chronic hyperplastic candidiasis $(0.38 \%)$, and erythroplakia $(0.096 \%)$. The main risk factors for just lesions were found to be smoking, alcohol and age. The awareness among the population was found to be low [11].

Observation in this study was that most participants reported "pain" as their motive behind visiting the dentist while otherpatients visited the dentist for routine dental check-up. The percentage of patients visiting the dentist in the past 6 months is low. The results do not concur with the aforementioned importance of regular dental visits and check-ups. It could be noted that the majority of the participants are not aware of the importance of regular check-ups and more dental awareness campaigns should be held to educate people on the importance of dental visits. Moreover, a study could be done to address the reasons precluding patients from regular visits to the dentist.

The Prevalence of oral mucosal lesions among 314 patients attending the oral medicine and diagnosis clinics of Al-Quds University for oral lesions was 22\%, which is close to the study done by Al-Mobeerek and Al-Dosari where the prevalence of oral lesions was $15 \%$ [4]. Other studies done in Turkey $41.7 \%$ [7], India $41.2 \%$ [6], and Spain 58.8\% [5] reported much higher prevalence of oral lesions. The most common lesion was recurrent aphthous ulcers $13.2 \%$. The etiology behind this lesion is not well identified but is thought to be multifactorial [9]. Factors implicated include: hormonal fluctuation, microelement deficiencies (such as vitamin B12), infections, genetic predisposition, systemic diseases, mechanical injuries, and stress [9]. Females were found to have more ulcers than males and a T-test revealed that females in the study sample were more stressed than males. In Kuwait, however, this lesion had $0.5 \%$ prevalence and the most common lesion detected was fordyces granules [8].

This study also found statistically significant correlation between smooth fissured leukoplakia and smoking. This emphasizes the importance of executing such investigations in order to examine the Palestinian individuals for intercepting currently active diseases and probe the etiology behind them in order to prevent future cases from happening by targeting the risk factors. Oral lesions prevalence studies are important in assessing the risk factors behind the development of oral lesions and aide in constructing guidelines concerned with the early detection and management of those lesions. In a study done by Ali et al., the prevalence of lesions increased with older age, alcohol and tobacco consumption [8] stressing out the importance of adopting routine examination of the oral mucosa for adults [4].

The fact that the study has been done in the oral medicine clinic might have skewed the percentage of patients with lesions. In the University, patients either 
go directly to the oral medicine clinic or are referred to it from other departments when they have a condition/oral lesion that needs to be further investigated and/or diagnosed. This means that the number might be higher than it actually is for the Palestinian population since patients are intentionally referred to the oral medicine clinic if they have been found to have an oral mucosal lesion. Therefore, this study may not be representative of the prevalence of oral lesions among the Palestinian population and a larger-scale study must be done in order to assess that.

As a third world country, Palestine could benefit from incorporating a systematic approach to detecting oral lesions through proper diagnosis in the dental clinic. The integration of such a protocol into the curriculum of the dental school is the gateway for targeting lesions in their early stages. Oral cancer could be manifested as a potentially malignant lesion before becoming cancerous [2]. Early detection, counselling habit cessation, periodic re-evaluation and long-term follow-up of potentially malignant lesions such as lichen planus and leukoplakia is key for improving their prognosis [3] [8].

\section{Conflicts of Interest}

The author declares no conflicts of interest regarding the publication of this paper.

\section{References}

[1] Al-Mobeeriek, A. and Al Dosari, A.M. (2009) Prevalence of Oral Lesions among Saudi Dental Patients. Annals of Saudi Medicine, 29, 365-368. https://doi.org/10.4103/0256-4947.55166

[2] Al-Maweri, S.A., Alaizari, N.A. and Al-Sufyani, G.A. (2014) Oral Mucosal Lesions and Their Association with Tobacco Use and Qat Chewing among Yemeni Dental Patients. Journal of Clinical and Experimental Dentistry, 6, e460-e466. https://doi.org/10.4317/jced.51706

[3] Al-Maweri, S.A., Al-Jamaei, A.A., Al-Sufyani, G.A., Tarakji, B. and Shugaa-Addin, B. (2015) Oral Mucosal Lesions in Elderly Dental Patients in Sana'a, Yemen. Journal of International Society of Preventive \& Community Dentistry, 5, S12-S19. https://doi.org/10.4103/2231-0762.156152

[4] Mubarak, S., Hmud, A., Chandrasekharan, S. and Ali, A. (2015) Prevalence of Denture-Related Oral Lesions among Patients Attending College of Dentistry, University of Dammam: A Clinico-Pathological Study.

[5] Hatem, M., Abdulmajid, Z.S., Taher, E.M., El Kabir, M.A., Benrajab, M.A. and Kwafi, R. (2015) Benign Orofacial Lesions in Libyan Population: A 17 Years Retrospective Study. Open Dentistry Journal, 9, 380-387.

https://doi.org/10.2174/1874210601509010380

[6] Cury, P.R., Porto, L.P.A., dos Santos, J.N., e Ribeiro, L.S.F., de Aquino Xavier, F.C., Figueiredo, A.L. and Ramalho, L.M.P. (2014) Oral Mucosal Lesions in Indians from Northeast Brazil. Medicine (Baltimore), 93, e140. https://doi.org/10.1097/MD.0000000000000140

[7] Bassim, C.W., Fassil, H., Mays, J.W., Edwards, D., Baird, K., Steinberg, S.M., Cowen, E.W., Naik, H., Datiles, M., Stratton, P., Gress, R.E. and Pavletic, S.Z. (2015) 
Oral Disease Profiles in Chronic Graft versus Host Disease. Journal of Dental Research, 94, 547-554. https://doi.org/10.1177/0022034515570942

[8] Darwazeh, A.M. and Pillai, K. (1993) Prevalence of Tongue Lesions in 1013 Jordanian Dental Outpatients. Community Dentistry and Oral Epidemiology, 21, 323-324. https://doi.org/10.1111/j.1600-0528.1993.tb00785.x

[9] Darwazeh, A.M. and Almelaih, A.A. (2011) Tongue Lesions in a Jordanian Population. Prevalence, Symptoms, Subjects Knowledge, and Treatment Provided. Medicina Oral Patologia Oral y Cirugia Bucal, 16, e745-e749.

https://doi.org/10.4317/medoral.17098

[10] Hassona, Y., Scully, C., Almangush, A., Baqain, Z. and Sawair, F. (2014) Oral Potentially Malignant Disorders among Dental Patients. Asian Pacific Journal of Cancer Prevention, 15, 10427-10431. https://doi.org/10.7314/APJCP.2014.15.23.10427

[11] Sujatha, D., Hebbar, P.B. and Pai, A. (2012) Prevalence and Correlation of Oral Lesions among Tobacco Smokers, Tobacco Chewers, Areca Nut and Alcohol Users. Asian Pacific Journal of Cancer Prevention, 13, 1633-1637.

https://doi.org/10.7314/APJCP.2012.13.4.1633 